\title{
mapeamento do Biovolume de Plantas Aquáticas Submersas a Partir de Dados Hidroacústicos e Imagem Multiespectral de Alta ResoluÇão ${ }^{1}$
}

\author{
Mapping the Bio-volume of Submerged Aquatic Vegetation through Hydro-acoustic Data and \\ High-Resolution Multi-Spectral Imaging
}

SABO BOSCHI, L. ${ }^{2}$, GALO, M.L.B.T. ${ }^{3}$, ROTTA, L.H.S. ${ }^{4}$ e WATANABE, F.S.Y. ${ }^{4}$

\begin{abstract}
RESUMO - As plantas aquáticas têm papel fundamental no equilíbrio dos ecossistemas, porém seu crescimento desequilibrado pode obstruir canais, represas e reservatórios e afetar múltiplos usos da água. Em relação a plantas aquáticas submersas, a utilização de medidas de controle torna-se mais complexa, em face da dificuldade em mapear e quantificar volumetricamente as áreas colonizadas. Nessas situações, considera-se que o uso de dados hidroacústicos possibilite o mapeamento e a mensuração dessas áreas, auxiliando na elaboração de propostas de manejo sustentáveis desse tipo de vegetação aquática. Assim, o presente trabalho utilizou dados acústicos e a técnica de krigagem para realizar a inferência espacial do biovolume de plantas aquáticas submersas. Os dados foram obtidos em três levantamentos ecobatimétricos realizados em uma área de estudos localizada no rio Paraná, caracterizada por condições favoráveis para proliferação de vegetação aquática submersa e dificuldade de navegação. Para delimitar as áreas caracterizadas pela presença de plantas aquáticas submersas, utilizou-se uma imagem multiespectral de alta resolução espacial World View-2. O mapeamento do biovolume das plantas aquáticas submersas nas áreas de ocorrência do fenômeno foi realizado a partir da inferência do biovolume por krigagem e do fatiamento dos valores inferidos em intervalos de 15\%. A partir do mapa gerado, foi possivel identificar os locais de maior concentração de macrófitas submersas, com predominância de valores de biovolume entre 15-30\% e 30-45\%, confirmando a viabilidade da utilização da krigagem na inferência espacial do biovolume, a partir de medidas ecobatimétricas georreferenciadas e com o suporte de imagem de alta resolução espacial.
\end{abstract}

Palavras-chave: sensoriamento remoto acústico, inferência por krigagem, espacialização do biovolume, imagem de alta resolução.

\begin{abstract}
Aquatic plants play a key role in ecosystem balancing. However, their unbalanced growth can clog canals, dams, and reservoirs, affecting multiple uses of water. Control of submerged aquatic plants is a complex task due to the difficulty in volumetrically mapping and quantifying the colonized areas. In these cases, the use of hydro-acoustic data allows mapping and measuring these areas, helping formulate proposals for sustainable management of this type of aquatic vegetation. This study used the kriging technique and acoustic data to perform the spatial inference of the bio-volume of submerged aquatic plants. The data was obtained from three echobathimetric surveys conducted in a Parana River study area, characterized by the proliferation of submerged aquatic vegetation, hindering navigation. High spatial resolution multi-spectral imagery World View-2 was used to delimit the areas with submerged aquatic plants. The mapping of the bio-volume of submerged aquatic plants was conducted through the bio-volume inference using the Kriging technique and slicing of the inferred values at 15\% intervals. The map generated allowed identifying the areas of highest concentration of submerged macrophytes, which predominantly presented bio-volume values between 15-30\% and 30-45\%. This confirms the feasibility of using the kriging technique for bio-volume
\end{abstract}

Recebido para publicação em 12.1.2012 e aprovado em 23.6.2012.

2 Doutorado pelo PPGCC, FCT/UNESP, Rua Roberto Simonsen, no 305, 19060-900 Presidente Prudente-SP, $<$ leticiasabo@yahoo.com.br>; ${ }^{3}$ Profa., Dra., Dep. de Cartografia, FCT/UNESP, Presidente Prudente-SP, <mlourdes@fct.unesp.br>;

${ }^{4}$ Doutorandos no PPGCC, FCT/UNESP, Presidente Prudente-SP, <luizhrotta@yahoo.com.br>, <fernandasyw@yahoo.com.br>.

Planta Daninha, Viçosa-MG, v. 30, n. 3, p. 525-539, 2012 
spatial inference through geo-referenced ecobathimetric measurements and the support of high spatial resolution imagery.

Keywords: acoustic remote sensing, inference by Kriging, bio-volume spatial distribution, high-resolution imagery.

\section{INTRODUÇÃO}

As plantas aquáticas possuem importantes funções para a manutenção do equilíbrio dos ambientes aquáticos, pois atuam na proteção e estabilização das margens de rios e reduzem os efeitos da erosão. São fundamentais também na cadeia alimentar, na oxigenação da água e na absorção de nutrientes. Contudo, quando esse equilíbrio é alterado, pode ocorrer rápido e excessivo desenvolvimento dessas plantas aquáticas (Tanaka, 2000), causando obstrução de canais, represas e reservatórios, reduzindo a disponibilidade de água para uso (Cavenaghi et al., 2003), dificultando as atividades de pesca e recreação e promovendo o entupimento da tomada de água de turbinas de usinas hidrelétricas (Velini, 2000).

O crescimento indiscriminado de plantas aquáticas está associado à disponibilidade de nutrientes na água, o que faz com que o crescimento de organismos autotróficos seja acelerado, particularmente algas planctônicas (fitoplâncton) e plantas aquáticas. $\mathrm{O}$ aumento na disponibilidade de nutrientes é decorrente de um desequilíbrio no sistema, ocasionado pela construção de barragens e pela própria intensificação de atividades antrópicas nas bacias hidrográficas, normalmente sem planejamento ou controle, causando o carregamento de nutrientes para o leito dos rios, por meio do aporte de despejos domésticos, industriais e fertilizantes químicos empregados nos cultivos distribuídos por toda a bacia hidrográfica (Velini, 2000).

Entre os diversos problemas decorrentes da presença das plantas aquáticas, destacamse aqueles que afetam principalmente as usinas hidrelétricas, como, por exemplo, em períodos de alta turbulência da água, como em épocas muito chuvosas, as plantas aquáticas podem vir a se desprender do fundo, ficando livres na coluna d'água, onde, na maioria das vezes, chegam às grades que protegem a entrada de água para as turbinas, causando sérios problemas econômicos (Pitelli, 1998).
Das várias espécies submersas que proliferam nos reservatórios das usinas hidrelétricas do Estado de São Paulo, destacam-se Egeria densa e Egeria najas, nativas da América do sul, e Hydrilla verticillata, proveniente da Ásia, todas pertencentes à familia Hydrocharitaceae. Esse crescimento rápido e excessivo vem causando sérios problemas em corpos hídricos no Brasil (Henares et al., 2011; Sousa et al., 2009, 2010; Mormul et al., 2010).

Nesse contexto, o manejo das plantas aquáticas tornou-se objeto de diversos estudos, devido à disseminação de áreas infestadas e aos prejuízos provocados por esse tipo de vegetação em reservatórios de usinas hidrelétricas. Nesse último caso, o controle dessas infestações exige constante manutenção de grades de tomada de água das turbinas, o que muitas vezes interrompe a geração de energia. Devido a esses problemas e ao alto custo do controle mecânico, várias investigações vêm sendo realizadas com o intuito de otimizar o processo ou mesmo encontrar alternativas para um possivel manejo, como é o caso do controle químico e biológico. O controle químico vem sendo empregado em vários países, por promover resultado rápido e eficiente e por ser seguro para a vida animal quando utilizado dentro das recomendações técnicas (Cardoso et al., 2003; Pitelli et al., 2008; Henares et al., 2011). O controle mecânico, além do alto custo, promove o risco de coleta indevida de animais jovens e proporciona a dispersão de plantas com reprodução vegetativa (Mustafa et al., 2010). Já para o controle biológico, Miyazaki \& Pitelli (2003) citam algumas técnicas em que se utilizam peixes como agente predador dessas plantas, as quais apresentaram resultados satisfatórios.

A adoção de medidas de controle para o caso de plantas aquáticas submersas torna-se ainda mais complexa pelo fato de estas não emergirem na superficie do espelho d'água, dificultando tanto seu manejo quanto a detecção das áreas infestadas por meio do sensoriamento remoto (Galo, 2002; Rotta et al., 2011). 
Neste trabalho é proposto o mapeamento do biovolume de plantas aquáticas submersas a partir de dados hidroacústicos e de uma imagem de alta resolução espacial, a fim de servir como uma ferramenta útil, independentemente da medida de controle adotada.

As imagens mutiespectrais usadas nesta abordagem foram tomadas pelo mais recente sistema orbital de aquisição de cenas de alta resolução espacial. Esse sistema, denominado World View-2, foi lançado em 2009 pela empresa Digital Globe e o seu sensor dispõe de bandas espectrais adicionais em alguns intervalos de comprimentos de onda, que podem ser apropriadas para estudos específicos desenvolvidos em ambientes aquáticos (Digitalglobe, 2011).

Os dados de biovolume foram calculados a partir de medidas tomadas com um ecobatímetro digital e científico, modelo DT-X, produzido pela empresa BioSonics, o qual pode operar em diferentes frequências acústicas. Esse sistema, em caso de levantamento cinemático, pode ser configurado em uma embarcação de qualquer tamanho e profundidades rasas $(1 \mathrm{~m})$. Quando são feitas medidas sobre o alvo em estudo, o instrumento registra automaticamente a profundidade, a altura média da planta e a porcentagem de cobertura vegetal, permitindo derivar o biovolume. Como todos os dados coletados são georreferenciados, é possível também realizar a inferência espacial dessa variável.

Este trabalho foi realizado em uma área de estudos localizada no rio Paraná. Sua escolha deve-se ao fato de este se constituir em um dos principais rios das regiões Sul e Sudeste do Brasil e pela sua importância ecológica e econômica. $\mathrm{O}$ alto curso do rio Paraná tem sido intensamente estudado, tanto no trecho de maior atividade antrópica (decorrente em grande parte da construção de usinas hidrelétricas) quanto na sua extensão preservada (entre os reservatórios de Porto Primavera-SP e Itaipu-PR). Pelo fato de haver crescimento maciço de macrófitas aquáticas submersas no reservatório nessa região e pela sua proximidade de Presidente Prudente-SP (cidade na qual se desenvolve a pesquisa), a área selecionada reúne condições adequadas para o desenvolvimento dos objetivos propostos.
Diante do exposto, considera-se que, independentemente do método de controle utilizado, o mapeamento da distribuição espacial das plantas aquáticas e a estimativa do biovolume dessa vegetação submersa sejam fundamentais para a implantação de técnicas adequadas ao manejo, pois fornecem a localização e dimensão horizontal das áreas infestadas, assim como uma medida tridimensional, em porcentagem, que relaciona profundidade do corpo d'água, altura e cobertura por plantas submersas, expressa como biovolume.

\section{Caracterização do ambiente em estudo}

O reservatório da Usina Hidrelétrica Engenheiro Sérgio Motta, também chamada de Usina Hidrelétrica Porto Primavera, pertence à CESP e está localizado no rio Paraná, $28 \mathrm{~km}$ a montante da confluência com o rio Paranapanema; trata-se da segunda maior hidrelétrica do Estado de São Paulo, totalizando $1.814 \mathrm{MW}$ de potência final, o que corresponde a $23 \%$ de toda a potência instalada pela CESP no Estado (CESP, 2011).

A barragem do reservatório de Porto Primavera, a mais extensa do Brasil, possui $10.186,20 \mathrm{~m}$ de comprimento, e seu reservatório, $2.250 \mathrm{~km}^{2}$. O processo de enchimento do reservatório da Usina Sergio Motta teve início em 7 de novembro de 1998; a primeira etapa de enchimento, na cota de 253,00 m, foi concluída em 14 de dezembro de 1998. Em 26 de março de 2001 foi concluída a segunda etapa do processo de elevação do nível do reservatório, passando da cota de $253 \mathrm{~m}$ para a de $257 \mathrm{~m}$ (CESP, 2011).

Para localização da área de estudos foi elaborada a Figura 1. Inicialmente, é mostrada a localização do reservatório de Porto Primavera no contexto do Estado de São Paulo e, em uma composição colorida de bandas espectrais do sensor TM/Landsat, grande parte da área inundada, com delimitação da área selecionada para o presente estudo. $\mathrm{Na}$ parte superior direita da figura, incluiu-se uma composição colorida da imagem multiespectral obtida pelo sistema WorldView-2, mostrando mais detalhes da área de estudos.

O sistema World View-2 dispõe de um sensor com bandas espectrais adicionais em 


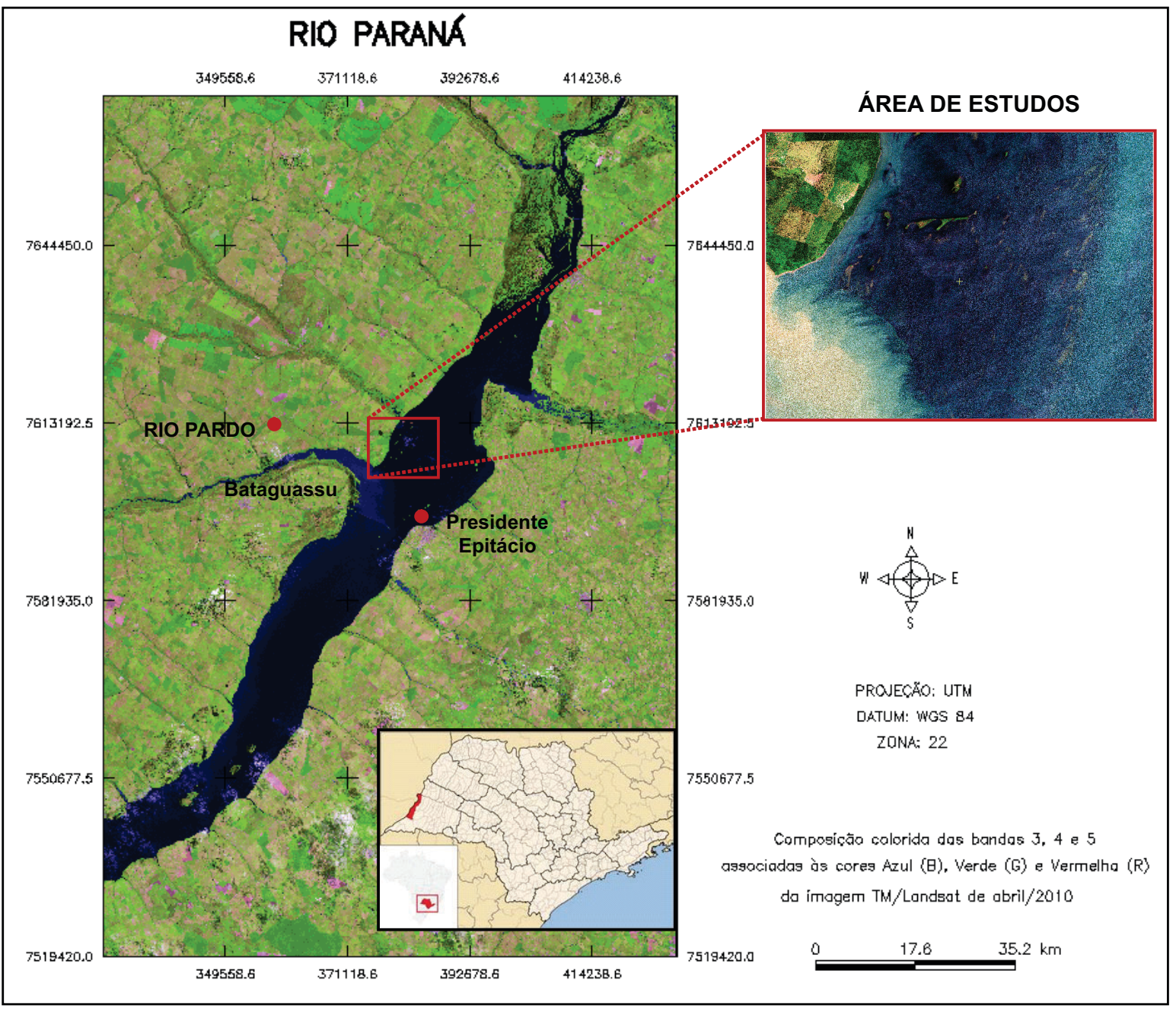

Figura 1 - Localização do reservatório de Porto Primavera no Estado de São Paulo; composição colorida de imagem TM/Landsat, mostrando o reservatório. No detalhe, imagem de alta resolução World View-2, indicando a área de estudos selecionada.

alguns intervalos de comprimentos de onda, que podem ser apropriadas para estudos específicos desenvolvidos em ambientes aquáticos. Esse sistema fornece imagens de alta resolução espacial $(1,8 \mathrm{~m})$ em oito bandas multiespectrais, sendo considerado um sensor multiespectral diferenciado, já que a inclusão de quatro novas bandas espectrais, além das tradicionais: costal (comprimento de onda entre 400 e $450 \mathrm{~nm})$, amarelo (585-625 nm), vermelho limitrofe (705-745 $\mathrm{nm})$ e infravermelho próximo 2 (860-1.040 nm), aumenta as possibilidades de aplicação das cenas dele (Digital Globe, 2011).

A imagem adquirida para este estudo foi tomada em 30 de dezembro de 2010. Na composição colorida dessa imagem, mostrada em destaque na Figura 1, os tons muito claros que ocorrem próximos à margem direita do rio Paraná, na região da foz do rio Pardo, estão associados aos maiores valores de turbidez (relacionado com maior concentração de sedimentos em suspensão). Já a região representada em tons mais escuros refere-se à área que foi inundada sem a retirada da vegetação original e que possui grande quantidade de "paliteiros" (troncos total ou parcialmente submersos), os quais dificultaram a navegação em grande parte da área de estudo, pelo fato de o sensor ecobatimétrico estar posicionado a $0,5 \mathrm{~m}$ de profundidade. É nessa região também que são encontrados os grandes bancos de macrófitas aquáticas submersas. 
Aquisição e processamento dos dados hidroacústicos

Os levantamentos in situ, realizados para aquisição de dados hidroacústicos, foram todos georreferenciados. O posicionamento das amostras no corpo d'água foi feito em tempo real, utilizando um GPS SPS361 integrado ao ecobatímetro, o qual recebe correções do tipo OmniSTAR VBS, possibilitando posicionamento em tempo real e disponibilidade instantânea de dados precisos. Trata-se de um serviço de abrangência global para o fornecimento de dados de correção GPS (Global Positioning Satellite) via satélites em tempo real. Mais detalhes podem ser obtidos no website do serviço (http: / /www.omnistar.com/).

Os dados hidroacústicos utilizados neste trabalho foram adquiridos em três levantamentos de campo, realizados em diferentes regiões da área de estudo, utilizando um ecobatímetro digital que opera, simultaneamente, em duas frequências.

O ecobatímetro é um instrumento de propagação sonora simples e muito utilizado para detectar a profundidade do corpo d'água (batimetria), bem como a presença ou ausência, abundância, distribuição, tamanho e o comportamento de plantas e animais submersos. O sensoriamento hidroacústico (termo geral para o estudo e aplicação do som na água) é capaz de inferir a distância a um objeto, calculada em função da velocidade do som, e o tempo que o eco leva para retornar (Biosonics, 2008). Trata-se de um instrumento eletrônico que possui um transmissor e um receptor acústico e, quando conectado a um transdutor subaquático, detecta objetos submersos. O transdutor converte o sinal elétrico de um emissor em um pulso acústico, transmite essa energia através da água, recebe os ecos (do alvo na coluna d'água e do fundo) e os converte em sinais elétricos. Quando o pulso acústico encontra um objeto, como um peixe ou o fundo, parte da energia (o eco) é refletida de volta para o transdutor. A distância do ponto mais alto da manifestação do sinal é proporcional ao tempo necessário para o pulso percorrer a distância do transdutor ao alvo e voltar. Se a velocidade na água for conhecida (em geral $1.500 \mathrm{~m} / \mathrm{s}$ ), a distância pode ser calculada a partir do tempo da viagem (Lurton, 2002).
Para o desenvolvimento deste projeto foi utilizado um ecobatimetro digital e científico, modelo DT-X, produzido pela empresa BioSonics, o qual pode operar nas frequências de 38, 70, 120, 200, 420 e $1.000 \mathrm{kHz}$. No presente trabalho foi utilizada a frequência de $200 \mathrm{kHz}$. Esse sistema, em caso de levantamento cinemático, pode ser configurado em uma embarcação de qualquer tamanho e em profundidades rasas $(1 \mathrm{~m})$; quando os transectos são feitos sobre o alvo em estudo, o ecobatímetro automaticamente registra a profundidade, a altura média da planta e a porcentagem de cobertura vegetal. Os dados coletados são georreferenciados, pois o sistema trabalha com um GPS integrado, aumentando assim a confiabilidade e acurácia do levantamento, em virtude da alta precisão posicional do GPS (Biosonics, 2008).

Os dados foram adquiridos a partir da realização de transectos nas áreas com maior probabilidade de presença de vegetação submersa e com navegabilidade segura, pois o sensor hidroacústico fica posicionado abaixo da superfície da água, o que pode provocar choque com galhos de árvores submersas, na presença de paliteiros.

Como mostrado na Figura 2, durante a tomada de dados, o transdutor do ecobatímetro é posicionado verticalmente a uma profundidade de 0,5 $\mathrm{m}$ em uma das laterais do barco. Na extremidade da mesma haste é colocada a antena do GPS, neste caso, o modelo SPS361 da Trimble, que é capaz de gerar e enviar via protocolo NMEA - as coordenadas geográficas pós-processadas in situ, com precisão submétrica, juntamente com as profundidades a elas associadas.

Os dados obtidos pelo ecobatímetro são visualizados em tempo real e armazenados em arquivos individuais para cada transecto, em um notebook conectado ao ecobatímetro através da porta ethernet. O sistema é controlado pelo software Visual Acquisition (da BioSonics Inc.), o qual fornece um display contínuo do ecograma, cuja interface é mostrada na Figura 3 , com o intuito de exemplificar a representação de águas rasas com a presença de macrófitas aquáticas submersas. Para detecção de vegetação submersa, é necessário configurar adequadamente o aplicativo Visual Acquisition. Neste estudo foram utilizados os

Planta Daninha, Viçosa-MG, v. 30, n. 3, p. 525-539, 2012 


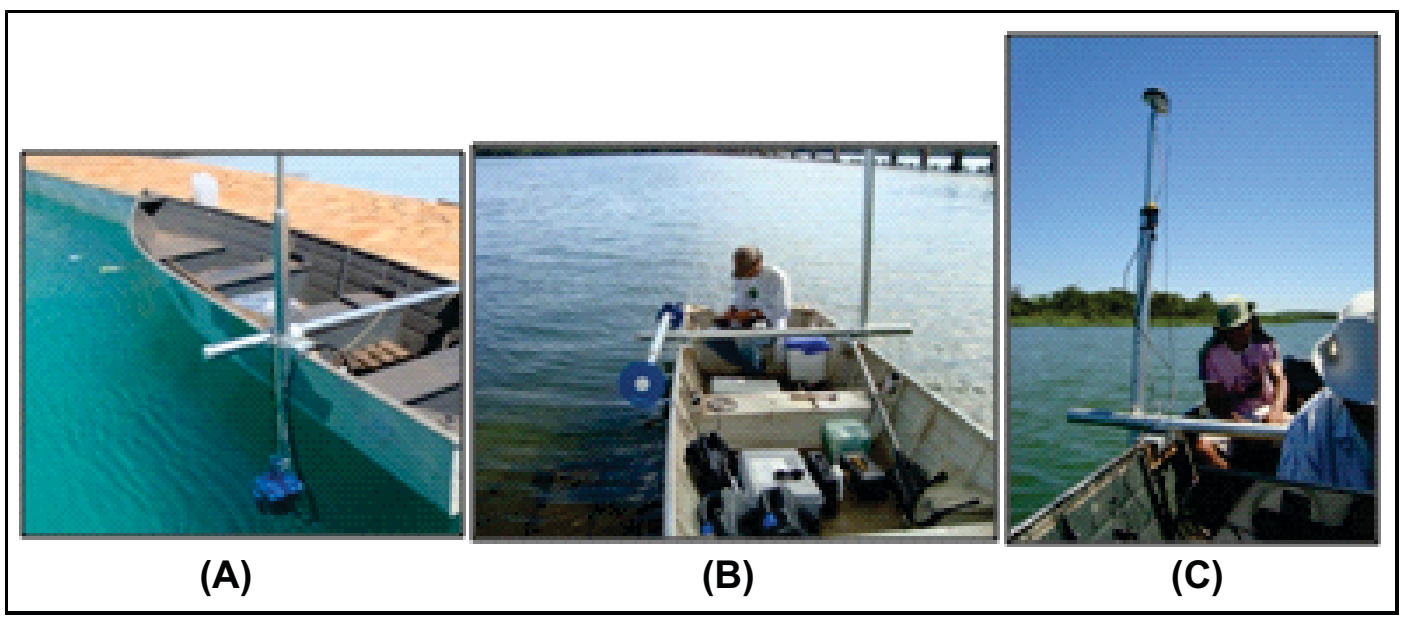

Figura 2 - Posição do transdutor durante operação do ecobatímetro (A); equipamento completo (ecobatímetro e GPS) (B); instrumentos em operação (C).

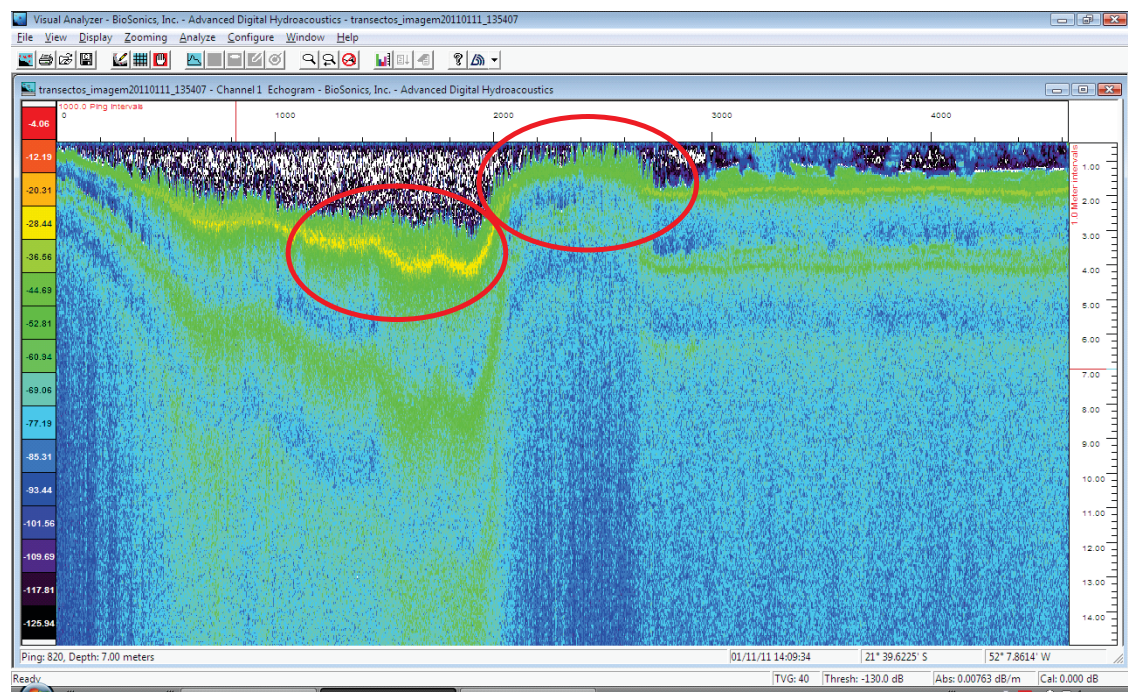

Figura 3 - Exemplo de ecograma produzido pelo software Visual Acquisition, mostrando o relevo do fundo e as áreas com presença da vegetação submersa.

valores recomendados por Sabol (2003) e mostrados na Tabela 1 .

A aquisição dos dados hidroacústicos foi feita em modo contínuo, a partir da navegação em transectos posicionados na área de estudo, em três diferentes levantamentos ecobatimétricos, realizados nos dias 13 e 14 de abril de 2010, 27 e 28 de novembro de 2010 e no período de 11 a 14 de janeiro de 2011 . Os transectos de novembro/2010 foram numerados de 1 a 7 ; os de abril/2010 receberam os números 8 e 9; e aqueles efetuados em janeiro/2011 foram reunidos e associados ao número 10, conforme representado na Figura 4. Nos levantamentos de 2010, foram delineados transectos que permitiram uma densa amostragem em uma pequena área, diferentemente do procedimento adotado na coleta de 2011, na qual se optou pela definição de transectos mais longos, com o objetivo de uma caracterização mais abrangente da área de estudos. Em ambos os casos, não foi possivel uma amostragem sistematizada da área nem definir transectos regulares, devido à dificuldade de navegação em decorrência da presença de paliteiros. 
Tabela 1 - Configuração do ecobatímetro utilizada na detecção de plantas submersas

\begin{tabular}{|c|c|c|}
\hline \multicolumn{2}{|c|}{ Parâmetro } & Valor e configuração \\
\hline Receptor & Modo de operação & Feixe simples \\
\hline \multirow{4}{*}{ Parâmetros de coleta de dados } & Profundidade mínima & $0 \mathrm{~m}$ \\
\hline & Profundidade máxima & $50 \%$ maior que a máxima profundidade \\
\hline & Valor limiar & $-130 \mathrm{db}$ \\
\hline & Modo limiar & Quadrático \\
\hline Parâmetros ambientais & $\begin{array}{l}\text { Temperatura } \\
\text { Profundidade } \\
\mathrm{pH} \\
\text { Salinidade }\end{array}$ & $\begin{array}{l}\text { Valores importantes para calcular a velocidade } \\
\text { do som e absorção. O uso de valores exatos para } \\
\text { águas rasas não é crítico. }\end{array}$ \\
\hline \multirow[b]{2}{*}{ Opções de armazenamento de dados } & Criação automática do arquivo de dados & Por tempo, 30 minutos \\
\hline & Nome do arquivo & $\begin{array}{l}\text { Nome é gerado com o horário do início de cada } \\
\text { coleta (a cada } 30 \text { minutos) }\end{array}$ \\
\hline \multirow{2}{*}{ Controle do pulso } & Taxa de emissão & 5 pps (pings por segundo) \\
\hline & Duração do pulso & $0,1 \mathrm{~ms}$ \\
\hline Modo acústico & Modo & Transmissão ativa \\
\hline
\end{tabular}

Fonte: Sabol (2003).

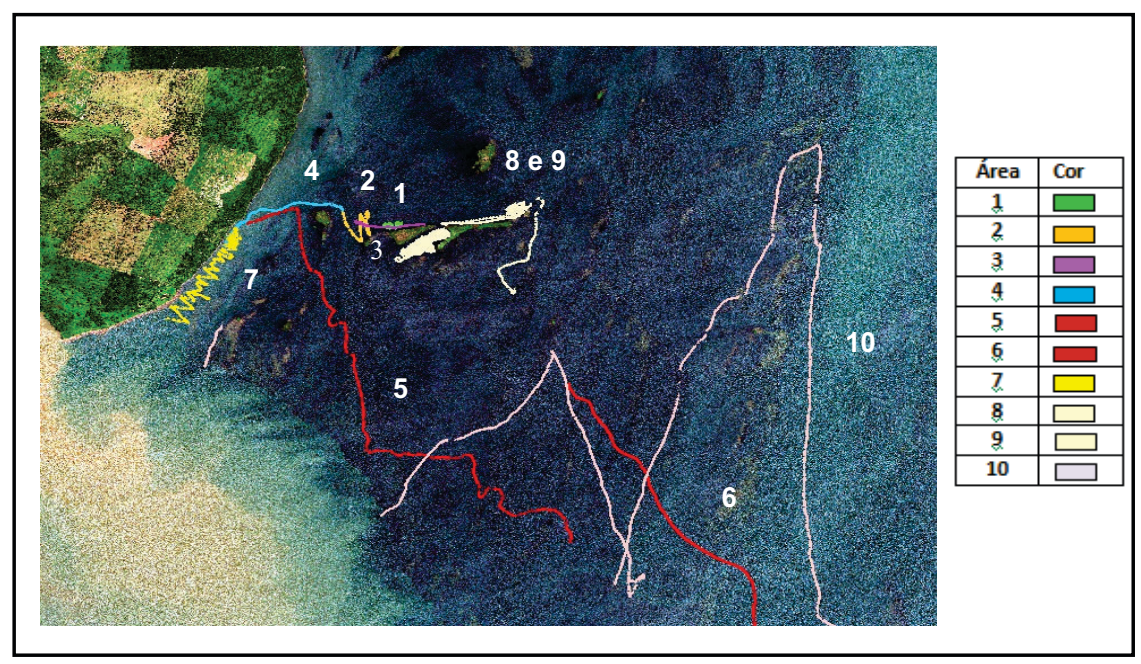

Figura 4 - Indicação dos transectos realizados em abril/2010 (8 e 9), novembro/2010 (1 a 7) e janeiro/2010 (10), sobrepostos a composição colorida da imagem WorldView-2.

Os conjuntos de dados adquiridos pelo ecobatímetro foram processados usando o software EcoSAV. Esse aplicativo, juntamente com o ecobatímetro DT-X, tem sido usado pelos pesquisadores de vegetação aquática submersa para estimar e localizar as numerosas espécies de vegetação aquática submersa tanto em ambientes marítimos quanto em ambientes lacustres. É um software de pós-processamento capaz de adquirir informações a respeito de vegetação aquática submersa (presença ou ausência), profundidade, altura média das plantas, porcentagem da cobertura vegetal, posição, dia e horário (Biosonics, 2008).

A estimativa dos parâmetros de saída do Ecosav considera que cada eco corresponde a um ping (pulso) único e o conjunto de 10 pings representa um ciclo, de modo que a porcentagem de cobertura vegetal é obtida pela razão entre o número de pings no ciclo que são classificados com presença de planta e o número de pings adquiridos; a altura média da planta 
é simplesmente a média de altura das plantas para os pings classificados como planta, e as posições são expressas pelo ponto médio entre os registros de coordenadas GPS no início e final de cada ciclo.

Os parâmetros de saída do EcoSAV (profundidade, altura da planta e porcentagem de cobertura vegetal) permitem estimar o biovolume da vegetação aquática submersa. Essa estimativa é uma métrica que leva em consideração a altura da planta, a profundidade e a porcentagem de cobertura (Schriver et al. 1995; Burks et al. 2001; Valley \& Drake, 2007), é obtida a partir da Equação 1 .

$$
\text { Biovolume }(\%)=\frac{\text { Alturada Planta }}{\text { Profundidade }} *(\text { Cobertura })
$$

em que altura da planta = média da altura da planta somente para os pings com presença de plantas; profundidade $=$ registrada pelo software de aquisição, o EcoSAV utiliza um algoritmo que assegura que a profundidade declarada como inferior não está dentro da cobertura vegetal (BioSonics, 2008); e cobertura $=$ a porcentagem de todos os pings que informam a presença de plantas.

De posse do biovolume, da altura da planta e da profundidade para cada um dos pontos, a média e o desvio-padrão para cada um dos transectos foram calculados, com o objetivo de caracterizar o ambiente (Tabela 2). Como foram realizados 10 transectos e em cada um deles foram adquiridos mais de mil pontos, uma maneira de mostrar o comportamento generalizado dessas variáveis na área de estudos foi através da média e de desviopadrão. Os valores de média e desvio-padrão de profundidade, altura da planta e biovolume, para cada um dos transectos adquiridos nos levantamentos realizados, mostram que as maiores médias de altura de plantas e respectivos biovolumes foram obtidos nos levantamentos ecobatimétricos realizados em abril de 2010 (transectos 8 e 9) - mês do ano que caracteriza o início da estação mais seca e maior ocorrência de plantas aquáticas. Os transectos 4 e 7 definem as menores profundidades e biovolumes. $O$ transecto 10 apresentou alta variabilidade, tanto para profundidade quanto para altura de plantas e biovolume.

Os pontos amostrados durante a realização dos transectos numerados de 1 a 4 apresentam, na sua maioria, profundidade de Secchi com valores próximos aos da profundidade do corpo d'água e valores de turbidez baixos, chegando a um máximo de 6 NTU. Com base nessas informações, conclui-se que o desenvolvimento da vegetação aquática nessas regiões, de modo geral, é favorecido pela penetração da radiação no corpo d'água. Para o transecto 7, verificou-se também que em todos os pontos amostrados a profundidade de Secchi é próxima à profundidade do corpo d'água e os valores de turbidez estão em torno de 11 NTU - condições essas consideradas favoráveis ao desenvolvimento da vegetação aquática submersa.

Tabela 2 - Média e desvio-padrão da profundidade da água, altura e biovolume de plantas para os transectos adquiridos em abril de 2010 (8 e 9), novembro de 2010 (1 a 7) e janeiro de 2011 (10)

\begin{tabular}{|c|c|c|c|c|c|c|}
\hline \multirow{2}{*}{ Transecto } & \multicolumn{2}{|c|}{ Profundidade $(\mathrm{m})$} & \multicolumn{2}{|c|}{ Altura da planta (m) } & \multicolumn{2}{|c|}{ Biovolume (\%) } \\
\hline & Média & Desvio-padrão & Média & Desvio- padrão & Média & Desvio-padrão \\
\hline 1 & 2,4091 & 0,2677 & 0,8449 & 0,4120 & 36,0419 & 18,6602 \\
\hline 2 & 3,2339 & 0,6010 & 0,7655 & 0,2678 & 24,3500 & 9,8581 \\
\hline 3 & 2,9214 & 0,6207 & 0,8205 & 0,2697 & 29,2080 & 11,6172 \\
\hline 4 & 2,2834 & 0,5865 & 0,3986 & 0,2602 & 17,4911 & 9,5919 \\
\hline 5 & 3,0026 & 0,8306 & 0,8476 & 0,4408 & 29,3337 & 14,1362 \\
\hline 6 & 3,4644 & 1,0735 & 0,9059 & 0,3945 & 28,4202 & 13,2713 \\
\hline 7 & 2,1966 & 0,6306 & 0,1851 & 0,0637 & 9,1521 & 5,3732 \\
\hline 8 & 3,3562 & 0,4761 & 1,3493 & 0,2878 & 40,4503 & 8,0053 \\
\hline 9 & 3,3211 & 0,4059 & 1,3738 & 0,3171 & 41,3765 & 8,6991 \\
\hline 10 & 5,2108 & 2,5437 & 0,8985 & 0,7508 & 24,4781 & 19,7178 \\
\hline
\end{tabular}


Nos transectos 5 e 6 , o destaque está no desvio-padrão dos dados de biovolume, pois as médias, quando comparadas com aquelas dos transectos anteriores, não apresentam muita diferença. Isso é explicado pela distribuição dos transectos e pela sua orientação, os quais não foram realizados em zigue-zague e sim no sentido margem a margem, com o objetivo de verificar sua variabilidade.

Os transectos 8 e 9 apresentaram valores de profundidade que variaram pouco em relação aos anteriores, porém a altura e o biovolume de plantas foram significativamente maiores. Isso pode estar relacionado ao fato de que as profundidades de Secchi apresentam valores similares à profundidade local ou maiores que a altura da coluna d'água, o que implica dizer que a radiação penetra na coluna d'água, favorecendo o desenvolvimento da vegetação aquática submersa. Da mesma maneira ocorre com os valores de turbidez, que estão em torno de 16 NTU, não interferindo assim no desenvolvimento das plantas aquáticas submersas, por serem considerados baixos.

Por fim, tem-se o transecto 10 , que se refere ao trajeto realizado com o objetivo de avaliar toda a área coberta pela imagem, implicando maiores variações de profundidade, acompanhadas, nos pontos com plantas submersas, pela maior variabilidade no biovolume (Tabela 1).

\section{Inferência espacial do biovolume}

Para esse mapeamento, considerou-se inicialmente a necessidade de discriminar áreas para as quais foi detectada presença de plantas daquelas onde a vegetação submersa estava ausente. Como cada um dos transectos é constituído por pontos sequenciais georreferenciados, dos quais essa informação pode ser obtida, uma simples sobreposição dos transectos sobre a composição colorida de três bandas espectrais da imagem World View-2 permite discriminar aqueles onde foi detectada presença de plantas aquáticas submersas, representados na Figura 5. Nessa figura, os transectos representados como linhas tracejadas em vermelho indicam os pontos sem presença de plantas, estando localizados na foz do rio Pardo (região em tons mais claros, esbranquiçados, na imagem World View-2), onde foram registrados maiores valores de turbidez (31,6 NTU). Essa condição de ausência de vegetação submersa decorre da pequena penetração de luz na coluna d'água, devido à presença de sólidos em suspensão, que provocam atenuação da radiação (Dekker, 1993). Isso pode ser confirmado pelos valores de Secchi nessa região, que atingiu $3 \mathrm{~m}$, enquanto a profundidade máxima foi de $8 \mathrm{~m}$.

Ainda na Figura 5, percebe-se nitidamente na imagem uma alteração na cor da água para os pontos a partir dos quais o ecobatímetro registrou presença de vegetação submersa, passando de uma tonalidade esbranquiçada para um azul mais intenso, criando uma condição espectral favorável à utilização da imagem multiespectral WorldView-2 na discriminação entre locais com e sem plantas aquáticas submersas. Assim, a imagem foi classificada utilizando um algoritmo de classificação não supervisionada por regiões, disponivel no software Spring 5.1.6, produzindo a representação temática das áreas caracterizadas pela presença e ausência de vegetação aquática submersa (Figura 6). Adicionalmente, para a inferência espacial do biovolume, foi considerada apenas a área de ocorrência de plantas aquáticas, excluindo-se da superficie interpolada áreas de terra firme (margem e ilhas) e corpo d'água com pequena ou nenhuma probabilidade de ocorrência de vegetação submersa.

A inferência espacial do biovolume na região associada, com base na classificação da imagem, à ocorrência de planta foi a técnica de krigagem, pois, segundo Rotta (2011) e Valley et al. (2005), essa técnica de interpolação apresentou bons resultados quando comparada a outras.

A krigagem compõe um conjunto de técnicas geoestatísticas de ajuste usadas para aproximar dados partindo do princípio de que, fixado um ponto no espaço, os pontos de seu entorno são mais relevantes do que os mais afastados. Isso pressupõe a existência de correlação entre os dados, deixando implícita a necessidade de saber até onde, espacialmente, essa correlação é significativa (Isaaks \& Srivastava, 1989).

Planta Daninha, Viçosa-MG, v. 30, n. 3, p. 525-539, 2012 
A diferença entre a krigagem e outros métodos de interpolação linear é a maneira como os pesos são atribuídos aos diferentes elementos. Além disso, essa técnica fornece, em média, estimativas não tendenciosas e com variância mínima, o que significa dizer que, em média, a diferença entre os valores estimados e verdadeiros para o mesmo ponto deve ser nula e que os estimadores possuem a menor variância entre todos os estimadores não tendenciosos (Camargo, 1997).

A técnica de krigagem extrai informações a partir do semivariograma, a fim de encontrar pesos ótimos a serem associados às amostras para estimativa do valor em um determinado ponto (Landim, 2003). O semivariograma é uma função intrínseca que reproduz a estrutura do fenômeno estudado, medindo as relações estatísticas (pelas covariâncias) que existem entre as amostras espaçadas por sucessivos valores predeterminados (Andriotti, 2003). Desse modo, a função do semivariograma deve ser modelada de modo a descrever a variação espacial e, consequentemente, poder estimar ou prever valores em lugares não amostrados e em grandes blocos por meio da krigagem (Webster \& Oliver, 2007).
O processo de modelagem considera uma série de decisões tomadas pelo usuário, as quais precisam ser apoiadas por dados experimentais ou informações auxiliares, relacionadas com (Goovaerts, 1997): a definição dos parâmetros do semivariograma (Figura 7); o

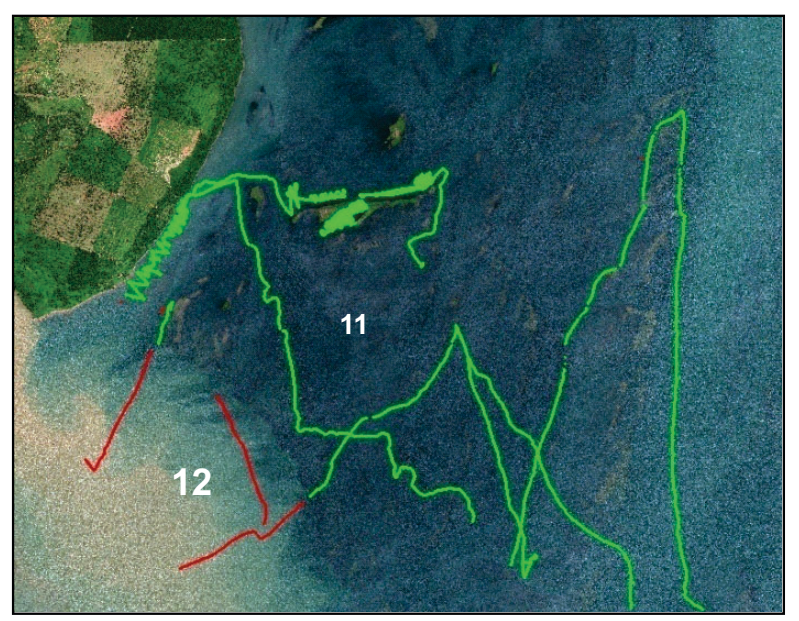

Figura 5 - Representação dos transectos, indicando locais com detecção da presença de plantas submersas (em verde) e com ausência de plantas (em vermelho), sobrepostos à composição colorida do World View-2.

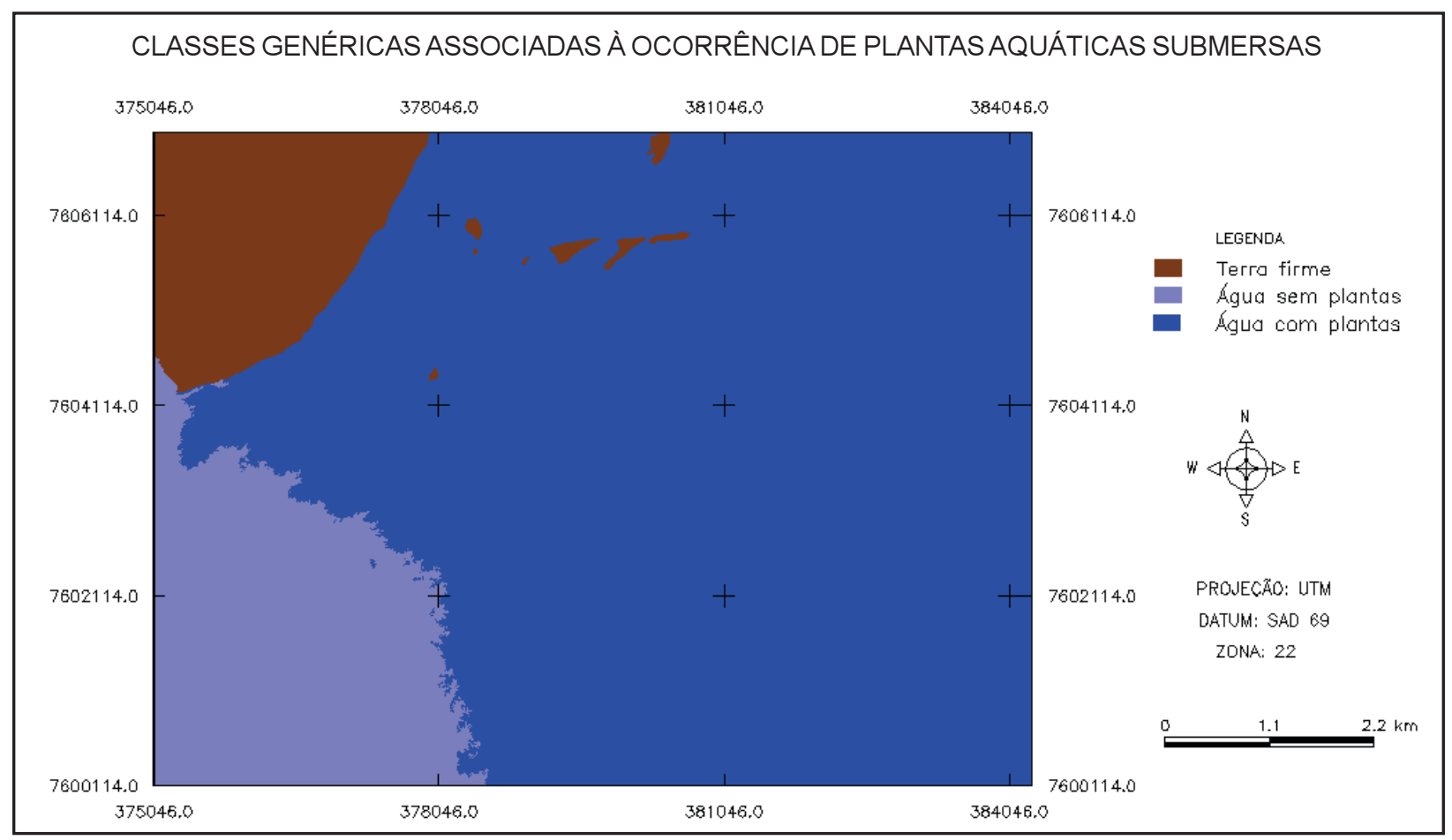

Figura 6 - Classes genéricas associadas à ocorrência de plantas aquáticas submersas. 


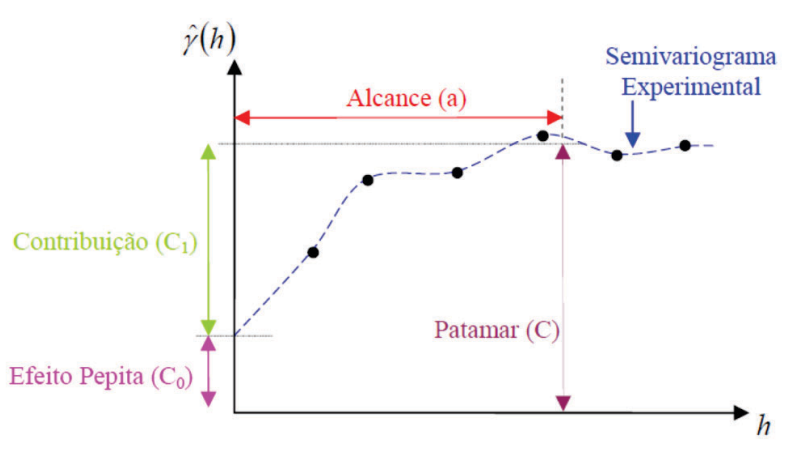

Fonte: Adaptado de Camargo (1997).

Figura 7 - Indicação dos parâmetos do semivariograma.

modelo a ser utilizado para fazer o ajuste (isotrópico ou anisotrópico); e o tipo de modelo teórico de semivariograma adotado (modelo esférico, exponencial, gaussiano ou combinados).

Os principais parâmetros do semivariograma, mostrados na Figura 7, são:

- Alcance (a): representa a distância máxima para a qual os elementos amostrais apresentam dependência espacial.

- Patamar (C): é o valor correspondente ao seu alcance no semivariograma, considerando que a partir desse ponto não existe mais dependência espacial entre as amostras, porque a variância da diferença entre os pares de amostras torna-se aproximadamente constante.

- Efeito pepita $\left(\mathrm{C}_{0}\right)$ : valor da semivariância para a distância zero; representa a componente da variabilidade espacial que não pode ser correlacionada com uma causa específica.

- Contribuição $\left(\mathrm{C}_{1}\right)$ : é a diferença entre o patamar e o efeito pepita.

Entre os diversos métodos de krigagem disponiveis, utilizou-se no presente trabalho a krigagem ordinária, que é uma técnica de estimação linear para uma variável regionalizada que atende à hipótese intrínseca e que não requer o conhecimento prévio da média. Assume-se a hipótese de quase-estacionaridade, também denominada estacionaridade local (Landim, 2003).

Considerando a estimação pontual primeiramente, estima-se $Z$ no ponto $x_{0}$ por $\left.[Z(x)] \downarrow 0\right)$ (Webster \& Oliver, 2007):

$$
Z\left(x_{0}\right)=\sum_{i=1}^{N} \lambda_{i} Z\left(x_{i}\right)
$$

em que $x_{0}$ é o ponto desejado; no $Z\left(x_{i}\right), i=1,2$, ....., $N, x_{i}$ são os pontos medidos; e $\lambda_{i}$ são os pesos atribuídos a eles.

A primeira etapa desse processo de interpolação foi a análise da anisotropia nas seguintes direções: $0^{\circ}, 30^{\circ}, 60^{\circ}, 90^{\circ}, 120^{\circ}$ e $150^{\circ}$. Dentre essas, a de maior alcance foi a de $0^{\circ}$ e a ortogonal, de $90^{\circ}$. Dessa maneira, o semivariograma foi modelado primeiramente para a direção de menor alcance $\left(90^{\circ}\right)$ e, na sequência, para a de maior alcance $\left(0^{\circ}\right)$. A Tabela 3 apresenta os parâmetros definidos para o semivariograma, e a Figura 8, os semivariogramas obtidos nessas direções. Analisando os dois semivariogramas, verifica-se que na direção de $0^{\circ}$ o alcance é maior, e a contribuição no modelo também.

Para realizar a inferência, foi utilizado o software Surfer 9.0, que possibilitou a interpolação da variável biovolume para cada célula de uma grade de espaçamento de $10 \times 10$ metros no terreno. Essa grade foi importada para o aplicativo Spring 5.1.6 e suavizada a partir de um filtro linear passa baixamédia, utilizando uma janela de $7 \times 7$ e cinco iterações. O efeito do filtro passa-baixa é a suavização da imagem e a redução do número de niveis de cinza da cena; assim, as altas frequências (transições abruptas) são atenuadas, conforme mostra a Figura 9.

Tabela 3 - Parâmetros do semivariograma ajustado

\begin{tabular}{|c|c|c|c|c|c|}
\hline Direção & Efeito pepita & Modelo matemático & Contribuição & Alcance & Razão Anisotropia \\
\hline $0^{\circ}$ & 50 & Gaussiano & 100 & 400 & 0,001 \\
\hline $90^{\circ}$ & 50 & Gaussiano & 53 & 280 & 1,000 \\
\hline
\end{tabular}




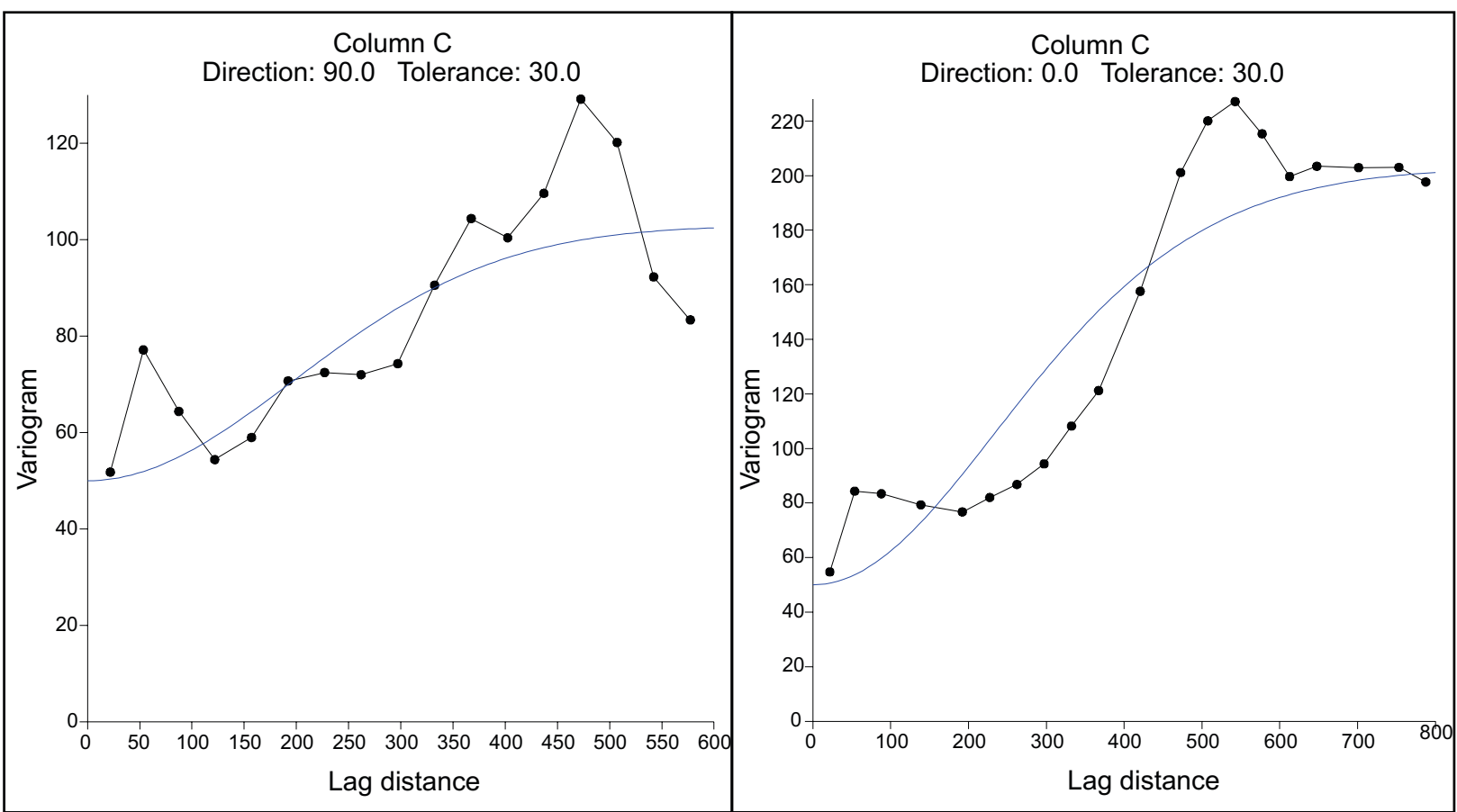

Figura 8 - Semivariograma para menor alcance à esquerda $\left(90^{\circ}\right)$ e para maior alcance à direita $\left(0^{\circ}\right)$.

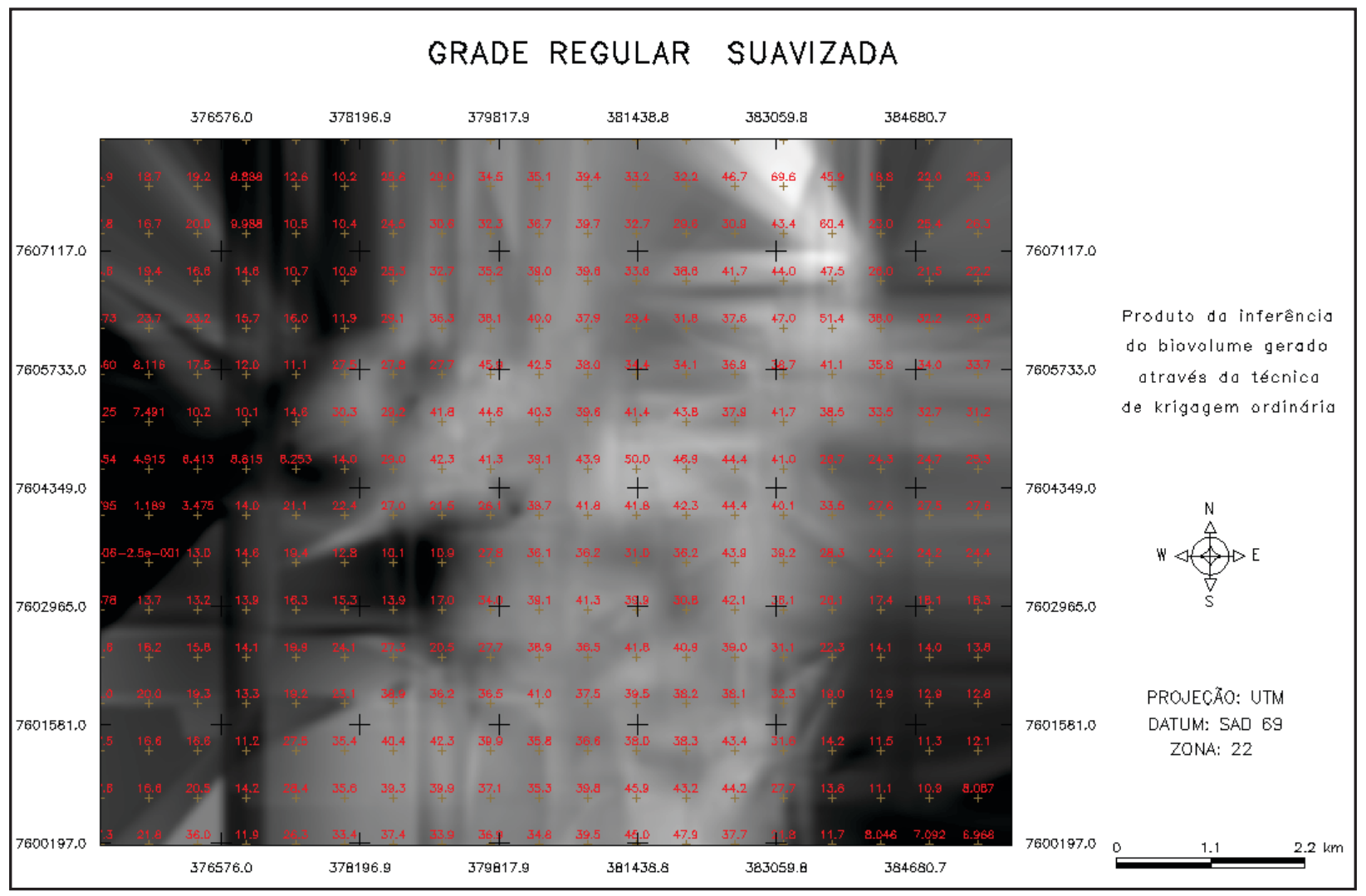

Figura 9 - Grade de interpolação do biovolume gerada pela técnica de krigagem. 


\section{RESULTADOS E DISCUSSÃO}

Com a suavização dos valores de biovolume interpolados por krigagem, foi realizado um fatiamento dos valores interpolados, considerando uma variação de $15 \%$ no biovolume. O processo de fatiamento consiste em definir intervalos de variação do biovolume (classes), com a finalidade de produzir um mapa temático. Assim, cada classe foi associada a um intervalo de variação da porcentagem de biovolume.

O mapa temático indicando as variações no volume de plantas aquáticas submersas é apresentado na Figura 10, em classes definidas com base nas porcentagens de biovolume estimadas, variando de 0 a $60 \%$. Na área considerada nessa análise $(8.501,92$ ha), verificase que em 6.691 ha ocorrem plantas aquáticas submersas em diferentes densidades, com predominância de regiões com biovolume de
$15-30 \%$ e $30-45 \%$. As classes de predominância de biovolume referem-se à região com concentração de paliteiros, havendo assim maior disponibilidade de nutrientes, o que acarreta um desenvolvimento acentuado da vegetação.

A classe de menor percentual de biovolume (0-15\%) concentra-se, principalmente, às margens do rio Paraná. Essa região é caracterizada por turbidez mais elevada do que das áreas de maior profundidade e grande influência do vento sobre a massa de água. A elevada atenuação da radiação combinada à presença do vento tornam a área pouco propícia ao desenvolvimento de vegetação aquática submersa.

Esse valor percentual de biovolume, apesar de não representar uma grandeza volumétrica, é uma quantificação útil para propostas de manejo de plantas aquáticas submersas,

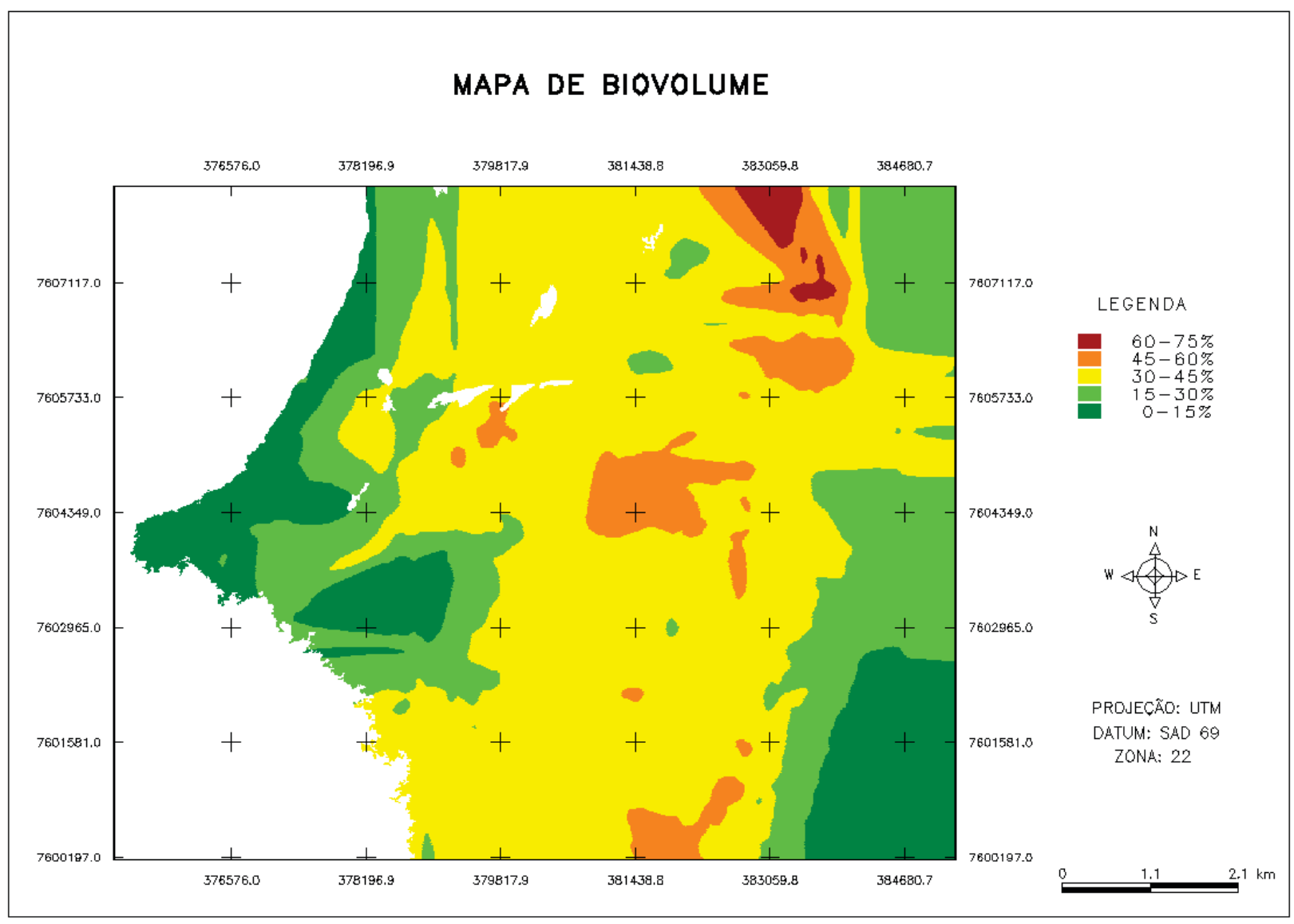

Figura 10 - Mapa temático do biovolume, variando em intervalos de 15\%. 
já que para sua estimativa inicial são levadas em conta a altura das plantas, a profundidade da água e a cobertura por plantas.

A fim de validar o resultado da inferência espacial obtida pela krigagem, foi realizada uma análise da concordância espacial entre os valores de biovolume interpolados, suavizados e fatiados, representados no mapa temático, e o biovolume foi calculado a partir das mediadas ecobatimétricas, de pontos com coordenadas correspondentes. Para esse procedimento, foi necessário que, antes do processo de inferência do biovolume por krigagem, 20\% dos pontos de cada transecto fossem retirados, gerando um novo arquivo para a validação da inferência. $O$ valor de concordância global obtido foi de 0,625 (840/1.344), indicando que $62,5 \%$ dos pontos medidos tiveram o valor de biovolume dentro do intervalo correto no mapa temático.

É importante ressaltar que, apesar de a qualidade do mapa gerado ter sido boa, este foi prejudicado pela distribuição dos transectos, por se tratar de uma área alagada sem retirada da vegetação, impossibilitando a navegação em determinadas áreas, pois o ecobatímetro está posicionado a $0,5 \mathrm{~m}$ de profundidade, não permitindo que os transectos fossem realizados de forma sistemática na área. No entanto, ainda adotando uma amostragem ecobatimétrica grosseira, o resultado obtido é adequado em aplicações que visem à identificação de áreas colonizadas por macrófitas submersas.

Diante do exposto, é possivel concluir que o objetivo de inferir espacialmente o biovolume da vegetação aquática submersa foi cumprido e que a utilização da técnica de krigagem mostrou-se satisfatória no mapeamento das áreas de dificil acesso. Assim, o mapeamento do biovolume dessa região pode contribuir na gestão do reservatório e numa estratégia de contenção desse tipo de vegetação.

\section{LITERATURA CITADA}

ANDRIOTTI, J. L. S. Fundamentos de estatística e geoestatística. São Leopoldo: Unisinos, 2003. 165 p.

BIOSONICS INC. Disponível em: <www.biosonicsinc.com>. Acesso em: 18 março 2008.
BURKS, R. L.; JEPPESEN, E.; LODGE, D. M. Littoral zone structures as Daphnia refugia against predators. Limnolol. Oceongr., v. 46, n. 2, p. 230-237, 2001.

CAMARGO, E. C. G. Desenvolvimento, implementação e teste de procedimentos geoestatísticos (krigagem) no sistema de processamento de informações georreferenciadas (SPRING). 1997. 106 f. Dissertação (Mestrado em Sensoriamento Remoto) - Instituto Nacional de Pesquisas Espaciais, São José dos Campos, 1997.

CARDOSO, L. R. et al. Sensibilidade a herbicidas de acessos de aguapé coletados em reservatórios do Estado de São Paulo. Planta Daninha, v. 21, n. 1, p. 61-67, 2003.

CAVENAGHI, A. L. et al. Caracterização da qualidade da água e sedimentos relacionados com a ocorrência de plantas aquáticas em cinco reservatórios da bacia do rio Tietê. Planta Daninha, v. 21, p. 43-52, 2003. (Edição Especial)

CESP. Usina Hidrelétrica de Porto Primavera.Disponível em: <www.cesp.com.br>. Acesso em: 10 abr. 2011.

DEKKER, A G. Detection of optical water quality parameters for eutrophic waters by high resolution remote sensing. 1993. $211 \mathrm{f}$. Tese (Ph.D. theses) - Free University, Amsterdam, 1993.

DIGITAL GLOBE. Disponível em: <www.digitalglobe.com> Acesso em: março de 2011

GALO, M. L. B. T. et al.. Uso do sensoriamento remoto orbital no monitoramento da dispersão de macrófitas nos reservatórios do Complexo Tietê. Planta Daninha, v. 20, n. 1, p. 7-20, 2002.

GOOVAERTS, P. Geostatistics for natural resources evaluation. New York: Oxford University, 1997.

HENARES, M. N. P. et al. Eficácia do diquat no controle de Hydrilla verticillata, Egeria densa e Egeria najas e toxicidade aguda para o guaru (Phallocerus caudimaculatus), em condições de laboratório. Planta Daninha, v. 29, n. 2, p. 279-285, 2011.

ISAAKS, E. H.; SRIVASTAVA, R. M. An introduction to applied geostatistics. New York: Oxford University Press, 1989. $561 \mathrm{p}$.

LANDIM, P. M. B. Análise estatística de dados geológicos. 2.ed. São Paulo: Unesp, 2003. 253 p.

LURTON, X. An introduction to underwater acoustics: principles and applications. New York: Spring, 2002

MORMUL, R. P. et al. Ostracod (Crustacea) colonization of a native and a non-native macrophyte species of Hydrocharitaceae in the Upper Paraná floodplain (Brazil): an experimental evaluation. Hydrobiologia, v. 644, n. 1, p. 185-193, 2010. 
MUSTAFA, A. L. et al. A experiência da CESP no manejo e controle de macrófitas no reservatório da UHE Souza Dias (Jupiá). Ação Amb., v. 13, n. 43, p. 17-26, 2010

MIYAZAKI. D. M. Y; PITELLI, R. A. Estudo do potencial do pacu (Piaractus mesopotamicus) como agente de controle biológico de Egeria densa, Egeria najas e Ceratophyllum demersum. Planta Daninha, v. 21, p. 53-59, 2003. (Edição Especial)

PITELLI, R. L. C. M. et al. Dinâmica da comunidade de macrófitas aquáticas no reservatório de Santana, RJ.

Planta Daninha, v. 26, n. 3, p. 473-480, 2008.

PITELLI, R. A. Macrófitas aquáticas no Brasil, na condição de problemáticas. In: WORKSHOP CONTROLE DE PLANTAS AQUÁTICAS, 1998. Anais... Brasília: IBAMA, 1998.

ROTTA, L. H. S. et al. Detecção de macrófitas submersas por meio de imagem QuickBird - Estudo de caso: usina hidrelétrica de Porto Colômbia - MG/SP. In: SIMPÓSIO BRASILEIRO DE SENSORIAMENTO REMOTO, 15., 2011, Curitiba. Anais... Curitiba: 2011. p. 4460-4467.

ROTTA, L. H. Inferência espacial para mapeamento de macrófitas submersas - Estudo de caso. 2011. 119 f. Dissertação (Mestrado em Ciências Cartográficas) Universidade Estadual Paulista, Presidente Prudente, 2011.

SABOL, B. M. Operating instructions manual for the acoustic - based submersed aquatic plant mapping system. West Palm Beach, FL. U.S. Army Corps of Engineers, 2003.

SCHRIVER, P. et al. Impact of submerged macrophytes on fish-zooplankton-phytoplankton interactions: large-scale enclosure experiments in a shallow eutrophic lake.

Freshwater Biol. v. 33, 2 , p. 255-270, 1995.
SOUSA, W. T. Z.; THOMAZ, S. M.; MURPHY, K. J. Response of native Egeria najas Planch. and invasive Hydrilla verticillata (L.f.) Royle to altered hydroecological regime in a subtropical river. Aquatic Bot., v. 92, n. 1, p. $40-48,2010$.

SOUSA, W. T. Z. et al. Environmental predictors of the occurrence of exotic Hydrilla verticillata (L.f.) Royle and native Egeria najas Planch. in a sub-tropical river floodplain: the Upper River Paraná, Brazil. Hydrobiologia, v. 632, n. 1, p. 65-78, 2009.

TANAKA, R. H. Eficácia de fluridone para o controle de Egeria ssp. em caixas d'água e em represa de pequeno porte sem fluxo de água. 2000. $157 \mathrm{f}$. Dissertação (Mestrado em Agricultura) - Universidade Estadual Paulista, Botucatu, 2000.

VALLEY, R. D.; DRADE, M. T.; ANDERSON, C. S. Evaluation of alternative interpolation techiniques for the mapping of remotely-sensed submersed vegetation abundance. Aquatic Bot., v. 81, n. 1, p. 13-25, 2005.

VALLEY, R. D.; DRAKE, M. T. What does resilience of a clear-water state in lakes mean for the spatial heterogeneity of submersed macrophyte biovolume? Aquatic Bot., v. 87, n. 4, p. 307-319, 2007.

VELINI, E. D. Controle de plantas daninhas aquáticas. In: CONGRESSO BRASILEIRO DA CIÊNCIA DAS PLANTAS DANINHAS, 22., 2000, Foz de Iguaçu. Anais... Foz de Iguaçu: SBCPD, 2000. p. 137-147.

WEBSTER, R.; OLIVER, M. A. Geostatistics for environmental scientists. London: John Wiley \& Sons, 2007. 